\title{
El MOVIMIENTO MAYA ESTATAL en GUATEMALA: LÓGICA MULTICULTURAL Y RECONFIGURACIÓN DEL CAPITAL
}

\author{
Sergio Palencia Frener
}

Resumen: Este trabajo es una crítica al movimiento maya en Guatemala enfocado en el Estado. Analiza la historia de la forma estatal contrainsurgente y cómo el paso hacia los gobiernos civiles, así como el proceso de firma de los Acuerdos de Paz, promovieron un discurso multicultural alejado de las demandas por la tierra y reclamos populares. Así pues, a partir de la teoría crítica, cuestiona la política mayanista que, insertándose en la burocracia estatal, da por sentada la lógica de las relaciones capitalistas. Esto con el fin de abrir la crítica al Estado y al Capital desde la posible particularidad revolucionaria de los grupos indígenas.

Palabras clave: movimiento maya estatal, rebelión social indígena, forma estatal, flujo de dominación, actividad social liberadora, particularidad en apertura revolucionaria.

Enviado a dictamen: 12 de octubre de 2011 Aprobación: 13 de diciembre de 2011 Revisiones: 1

Dr. Sergio Palencia Frener, Licenciado en Sociología por la Universidad del Valle de Guatemala. Actualmente en estudios de maestría en el posgrado del Instituto Alfonso Vélez Pliego, Benemérita Universidad Autónoma de Puebla. Correo electrónico: sergio.palenciaf@ gmail.com; sergiopf83@yahoo.com.mx.
Abstract: This is a critic of the Guatemaltan Maya movement focused in the state. It analyzes the history of the counterrevolutionary state form and how the transition to civil governments and the peace accords process, promoted a multicultural discourse very distant from the land demands and popular reclaims. From the critic theory this work questions the mayan bureaucratic politics that take for granted the capitalist relations logic. With this purpose this work tries to open the state and capital critic from the possible revolutionary particularity of indigenous groups.

Keywords: state focused maya movement, indigenous social rebellion, state form, flux of domination, liberating activity, particularity in revolutionary openness.

\section{Introducción}

$1 \begin{aligned} & \text { finales de } 1981 \text { se inició en Guatemala, de forma } \\ & \text { sistemática, la mayor campaña de exterminio } \\ & \text { contrainsurgente en la historia contemporánea }\end{aligned}$ de América Latina. El auge del movimiento guerrillero y el protagonismo popular en varias regiones del altiplano indígena, habían puesto en riesgo al Estado anticomunista. La huella de la rebelión social indígena y de la reacción exterminadora del Estado sigue latente en el país, estudiada y reflexionada de diversas maneras. Este trabajo es una reflexión de esa huella a partir del cuestionamiento del movimiento maya enfocado en el Estado. Primero, veremos cómo dicho movimiento toma por dadas formas políticas que refuerzan el statu quo y 
que derivan del multiculturalismo promovido durante el proceso de firma de los Acuerdos de Paz entre la guerrilla y el gobierno en 1996. Segundo, esbozaremos una teoría dialéctica del poder que cuestione al Estado y al capital como momentos constitutivos del flujo de dominación. Finalmente, haremos una crítica al movimiento maya estatal con el fin de abrir el debate en torno a la transformación radical de la sociedad y la apertura de la lucha no cernida bajo la forma estatal y capitalista.

\section{Del Estado contrainsurgente al Estado multicultural en Guatemala}

En este apartado estudiaremos la conformación y quiebre de la forma estatal en Guatemala a través de cuatro momentos centrales. El primero corresponde a la década revolucionaria (1944-1954), el segundo al Estado anticomunista contrainsurgente (1954-1982), el tercero a la fuerte lucha social del movimiento revolucionario (1960-1982), y el cuarto, al Estado surgido del exterminio contrainsurgente y la reconfiguración del capital a partir de 1983.

\section{a. De la dominación personalista-finquera a la lucha por la instauración del Estado moderno}

El 20 de octubre de 1944 es una fecha importante en la historia de Guatemala; esto debido a que, mediante un alzamiento militar apoyado por estudiantes, maestros y obreros en la capital, se logra romper con la dictadura de Jorge Ubico Castañeda (1931-1944). En plena efervescencia mundial por los ideales de democracia y lucha antidictatorial, el pequeño país centroamericano ingresaba a la posguerra con la elección presidencial de Juan José Arévalo, hombre dispuesto a reformar el Estado y consolidar procesos de modernización educativa, laboral y ciudadana. No obstante la algarabía inicial por la llamada Revolución de Octubre, poco a poco las políticas de Juan José Arévalo comenzaron a entrar en contradicción con las antiguas elites terratenientes e industriales. El principal desafío de los grupos que pretendían modernizar el Estado y las relaciones sociales en Guatemala era, precisamente, romper con la forma finquera-patriarcal del Estado y la sujeción semi-servil de la inmensa mayoría indígena en el país. En ese momento histórico, la agroexportación del café era el centro neurálgico en la acumulación de plusvalía, siendo la propiedad de la tierra en grandes fincas la que daba derecho al finquero sobre el trabajo semiservil de gran mayoría de indígenas. Tal como lo ha interpretado Sergio Tischler (2001), el Estado surgido de la Revolución Liberal de 1871 tuvo a la finca como centro de las relaciones sociales de dominación.

Juan José Arévalo percibió lo peligroso que era tocar el nervio vivo de la propiedad de la tierra. Ya las embajadas de EE.UU. e Inglaterra revisaban de cerca las reformas arevalistas, y los grupos reaccionarios de Guatemala, como la iglesia católica y la clase terrateniente e industrial, denunciaban el "comunismo" que se expandía en el país. Sin embargo, el mismo ímpetu de la Revolución de Octubre hacía que tales obstáculos fuesen vistos como normales frente a la necesaria modernización económica y política guatemalteca. Es así que con la elección como presidente de uno de los gestores de la caída del régimen ubiquista, Jacobo Árbenz Guzmán, llegaba un gobierno dispuesto a romper con las relaciones de dependencia hacia EE.UU. y que quería remplazar la dominación patriarcal-personalista del Estado finquero por la hegemonía moderna de un Estado capitalista. Para esto el gobierno de Árbenz decidió atacar el temido nervio de la tierra y los monopolios estadounidenses, atentando contra las condiciones que permitían la dominación social en la figura del terrateniente, fuese el finquero cafetalero nacional o la hegemonía estadounidense en la electricidad, los medios de comunicación o las plantaciones bananeras. Así pues, se creó un temor al supuesto comunismo que representaba Guatemala para el hemisferio y la hegemonía estadounidense, lo cual 
desencadenó la crisis de legitimidad gubernamental, la traición del ejército nacional y, finalmente, el derrocamiento del gobierno revolucionario de Jacobo Arbenz en 1954.

\section{b. El primer Estado contrainsurgente de América Latina en el contexto de la Guerra Fría (1954-1966)}

Si bien el impulso de transformación social promovido por el gobierno de Árbenz suele verse erróneamente como un esfuerzo local citadino ${ }^{1}$ y no de levantamiento rural, el ataque a la propiedad de la tierra era vital para romper con las relaciones de poder directaspersonalistas. ${ }^{2}$ Los Comités de Reforma Agraria habían llegado a crear vínculos de comunicación local-estatal que superaban las autoridades finqueras tradicionales. Esto había impulsado una lucha contra el trabajo forzado y el reclamo de tierras, donde, paulatinamente, trabajadores y mozos indígenas o ladinos, reclamaban sus derechos. ${ }^{3}$ Luego, con la intervención y respaldo de EE.UU. al Ejército de Liberación, comandado por Carlos Castillo Armas, se desató una verdadera "cacería de brujas" contra los "comunistas" y demás asociados al gobierno de Árbenz. El Estado de Guatemala pasó a ser constitucionalmente anticomunista en 1956 y a desconocer los derechos ciudadanos de todo aquel implicado en actividades consideradas subversivas, antinacionalistas y comunistas. El proceso de contrarrevolución no pudo regresar a la situación previa a 1944 del Estado finquero (Tischler, 2010), pero persiguió la organización campesina y convirtió toda demanda por la tierra en sinónimo de comunismo internacional, anticatolicismo y antinacionalismo (Vela, 2008). El Estado se consolidó así contra las luchas sindicales y campesinas, así como contra todo tipo de opciones políticas que dieran cabida a un cuestionamiento de la institucionalidad surgida de la reacción guatemalteca y la hegemonía estadounidense en la Guerra Fría.
Sin embargo, seguía abierta la crisis iniciada por la Revolución de Octubre, manteniendo vivo el cuestionamiento de la propiedad de la tierra y las relaciones semi-serviles. El Estado surgido de 1954 no pudo avanzar en la construcción de la legitimidad social y tuvo que enfrentarse a los primeros momentos de descontento: a) en 1960 se alza un grupo del Ejército inconforme con las políticas pro-imperialistas que denigraban la soberanía nacional; b) en 1962 grandes revueltas estudiantiles se desatan en la ciudad capital; c) las primeras guerrillas, inspiradas por el triunfo de la Revolución Cubana, se hacen presentes en la región oriental del país. En respuesta, se fue conformando un Estado anticomunista que daba preeminencia al Ejército como garante de la institucionalidad, al tiempo en que EE.UU. asesoraba los sistemas de inteligencia y las medidas de control ciudadano, así como la lucha antisubversiva. Dicha situación provocó un cierre político inminente y, tras el Golpe de Estado de 1966, la forma estatal represiva sostenida por el Ejército nacional termina configurando un Estado-Ejército basado en la contrainsurgencia y en la denegación del derecho ciudadano al considerado subversivo, comunista o guerrillero. El primer Estado contrainsurgente de América Latina se había creado en el contexto de la Guerra Fría. Guatemala pasó de ser el bastión de la democracia y el nacionalismo latinoamericano, al bastión de un Estado recuperado de las "garras del comunismo internacional" y la instauración de un modelo de control que evitara otra Revolución Cubana en el jardín trasero de EE.UU.

\section{c. Configuración de la negatividad social: lucha social y movimiento revolucionario (1960-1982)}

Los primeros focos guerrilleros en Guatemala se dieron en una región donde la presencia indígena no era mayoritaria, si bien las distinciones de adscripción suelen ser de ladinos: Ch'orti' y Poqomam. Grupos guerrilleros como las Fuerzas Armadas Rebeldes (FAR) 
y el Movimiento Revolucionario 13 de Noviembre (MR-13) buscaron internarse en la Sierra de las Minas, lugar estratégico en las comunicaciones nacionales y de posible apoyo campesino a la Revolución. Para ese entonces se consideraba que los pueblos indígenas del Altiplano Occidental no tenían potencial revolucionario y, más bien, formaban parte de la retaguardia reaccionaria de la iglesia católica y la élite terrateniente. Era claro que los primeros grupos guerrilleros reproducían en su estrategia los prejuicios del progreso y el avance de la conciencia de los pueblos. De cualquier manera la idea foquista de inspiración guevariana falló en la región oriental de Guatemala. La debilidad militar de la guerrilla y la gran ofensiva del ejército hizo naufragar el primer ciclo de contestación armada insurgente para 1966.

Si la idea de toma del poder de la guerrilla quería estar vigente, debía replantear su estrategia militar y de apoyo popular, tal como lo hizo Rolando Morán en el Documento de marzo (2008). En el mismo se planteaban los errores de la primera campaña insurgente en el oriente del país y la necesidad de buscar un nuevo territorio, una nueva estrategia de apoyo popular y nuevas condiciones para enfrentar al Estado contrainsurgente. Geográficamente propuso el altiplano indígena donde, según Morán, se encontrarían condiciones propicias para un nuevo ejército guerrillero. Entre 1967 y 1972 se apresuró el periodo constitutivo de la Nueva Organización Revolucionaria de Combate (NORC) la cual, más adelante, daría origen a la guerrilla más fuerte de la Guatemala de aquella época, el Ejército Guerrillero de los Pobres (EGP). Pero mientras esto proponía el estratega guerrillero, la población del altiplano indígena ya había iniciado una serie de cambios asociados con: a) la inserción de órdenes religiosas impulsadas por el Concilio Vaticano Segundo (1963), b) proyectos de asociación campesina de colonización de tierras estatales (Ixcán, 1966-1978), c) nuevas relaciones laborales tras la diversificación económica propiciada por el mercado internacional y el Mercado Común
Centroamericano, impulsándose la exportación del azúcar y del algodón en las cálidas tierras de la Costa Sur, y d) organización campesina y cooperativista.

Las condiciones de trabajo en las fincas de la Costa Sur y la dificultad de sobrevivir el resto del año en las propias tierras, cada vez más pobres, incidió en un descontento que se venía haciendo consciente y organizado entre 1967-1975. Lejos de considerar que la guerrilla habría de llevar la batuta vanguardista de la conciencia de cambio radical, en el altiplano se fermentaban ${ }^{4}$ y se realizaban procesos de lucha. La organización campesina y sindical en la Costa Sur, muchas veces impulsada por universitarios y abogados laboristas, hacían entrar en contacto diversos grupos sociales y étnicos del grueso sector explotado por la agroexportación. Ahora bien, el suceso que vino a desencadenar la organización social masiva y el incremento de la actividad pública guerrillera fue el terremoto de 1976. Dicho suceso desbordó las capacidades estatales y abrió las posibilidades de organización regional más allá de la localidad, permitió el contacto de grupos sociales y étnicos, contacto hasta el momento restringido y, sobre todo, evidenció la pobreza y marginación tanto a nivel urbano como rural. El ambiente reivindicativo se mostró con grandes huelgas en fábricas en la capital, así como la creación del Comité de Unidad Campesina (CUC), central en la lucha. Así también, la participación masiva de trabajadores se mostró en dos manifestaciones: a) la huelga y marcha de los mineros de Ixtahuacán en 1977 que inició con 72 sindicalistas y terminó con el ingreso a la capital de 150,000 personas; b) la gran huelga de la Costa Sur que paralizó la producción finqueraagroexportadora y obtuvo un aumento salarial por parte del gobierno militar de Lucas García en 1980.

El momento de intensidad más fuerte de lucha y agitación revolucionaria se dio entre 1978 y 1982, tanto por el impulso de la Revolución Sandinista como por el propio ambiente rebelde. A nivel capitalino, diversas organizaciones sindicales sostenían fuertes relaciones 
con grupos guerrilleros y exigían, en sus manifestaciones, la instauración de un gobierno revolucionario y antiimperialista. En el área rural, especialmente entre 1980 y 1982, el discurso y organización guerrillera fue confluyendo con el malestar causado por la represión del ejército y los procesos organizativos de reivindicación locales. Regiones indígenas de diversas etnias (chuj, akateko, k'iche, kaqchikel, ixil) en departamentos como Huehuetenango, Quiché, Sololá y Chimaltenango apoyaron principalmente al EGP. Sin embargo, según diversos testimonios presenciales, la disposición y apoyo al EGP se topó, a su vez, con una intensidad de levantamiento que muchos llaman preinsurreccional (Falla, 1993; Meoño, 2010, conversación personal) o de rebelión (Vela, 2008; Porras, 2009). Si así se constatara estaríamos ante un evento que ha pasado desapercibido en la historia, pero que constituye nada menos que una rebelión o preinsurrección de población indígena en apoyo a la guerrilla; incluso, por encima de los marcos organizativos de la misma. Es decir, un verdadero estallido social indígena, a pesar o junto a la perspectiva de toma del poder estatal de la guerrilla. Sin embargo, lo que se ha tendido a recordar del periodo de 1978 a 1983 ha sido la magnitud de represión y exterminio social con el cual el Estado contrainsurgente, a través del ejército y otros grupos clandestinos de derecha, asesinaron, torturaron y masacraron a todo aquel individuo o comunidad del que se sospechara apoyaba a la guerrilla. Finalmente, entre 1981 y finales de 1983 , el ejército había lanzado la ofensiva contrainsurgente desde la capital hasta los departamentos colindantes con México. El peor exterminio social de la América Latina contemporánea se había realizado para apagar la revolución y los focos de rebeldía. La especificidad de este exterminio social fue que, en la mayoría de los casos, se realizó como política de "tierra arrasada" contra población indígena desarmada del altiplano. La violenta verdad del Estado que hizo de los comunistas o campesinos rebeldes en las constituciones de 1956 y 1965 no-ciudadanos y no-humanos, se mostró como extensión de la dominación histórica concretada al temor de que "el indio baje de la montaña", lo cual, finalmente, dio como resultado que se considerara enemigo de Estado al indígena-subversivo-comunista. Una vez aplastada la rebelión e instaurado el terror, era hora de llamar a los capitales huidizos y de volver a hacer negocios bajo la democracia representativa.

\section{d. Reconfiguración del capital y forma actualizada del Estado guatemalteco (1982-2000)}

El 23 de marzo de 1982 un triunvirato militar, encabezado por el general Efraín Ríos-Montt, dio un Golpe de Estado para sustituir la continuidad de mando que se daría en las recientes elecciones. Se habló en ese entonces de un golpe conducido por "oficiales jóvenes" que traerían la legalidad al Estado e impulsarían cambios respecto a la brutalidad gobernante. Esto no resultó así, y se promovió una continuidad de las personas encargadas en la estrategia contrainsurgente, manteniéndose y profundizándose la campaña de "tierra arrasada", las masacres y el ordenamiento social de las comunidades del altiplano en Patrullas de Autodefensa Civil. Si bien en 1983 sectores del ejército decidieron relevar del gobierno al mismo Ríos-Montt, el proceso paralelo de contrainsurgencia y el regreso a la legitimidad institucional del Estado ya habían iniciado. El Estado de Guatemala había enfrentado desde 1978 una crisis de legitimidad creciente, además de ataques frontales de las élites económicas, que veían como "medidas autoritarias" las impuestas por el alza al salario mínimo del campo en 1980. De hecho, la particularidad de la crisis económica de Guatemala hacia 1980 no se debió enteramente a la deuda externa, como pasaría con México y Costa Rica, sino a la crisis social revolucionaria que debió afrontar el Estado y la crisis del modelo agroexportador reflejado en los precios internacionales. Así por ejemplo:

Las tasas de la endeble industrialización bajaron de manera fuerte durante los inicios de la década de 1980, 
así como el decrecimiento real de la actividad industrial. Para 1980 el porcentaje de aumento de crecimiento industrial había sido de 5.66\% comparado con el año anterior, mientras que el crecimiento industrial en 1981 había sido de $3.11 \%$, con un leve repunte de $5.21 \%$ en 1982 para, posteriormente, tener una drástica caída en 1983 con $1.89 \%$ y, finalmente, en 1984 el punto mínimo de la década con apenas 0.49\% (Dosal, 1997: 423). Asimismo las principales mercancías agrícolas tradicionales sufrieron una baja enorme en la cantidad exportada como lo podemos ver a través del análisis de diversos historiadores y economistas. Así por ejemplo, para el período 1980-1981 se habían exportado 2.505,549 de quintales café oro, no habiendo habido un nivel tan bajo en la exportación de dicha mercancía sino el período de 1975-76 con 2.591,913 de quintales de café oro (Wagner, 2001). Según Ayau (1993: 22) las exportaciones de café “[...] descendieron sensiblemente de un máximo de 175 millones de dólares en 1977 a 100 millones en 1981, manteniéndose debajo de 140 millones hasta después de 1985." Según la Comisión de Esclarecimiento Histórico (1997), "El conjunto de la actividad cafetalera tendió a estancarse durante toda la década de los ochenta, sin que pueda distinguirse nítidamente entre los efectos de la crisis externa y los de la crisis bélica." Así también el azúcar se encontró en crisis desde mediados de la década de 1970, cuando especialmente en el período de 1977 a 1979 hubo una abrupta caída de su precio internacional, los azucareros guatemaltecos afirman que tuvieron que dedicarse al "mantenimiento de la empresa", no siendo para nada casualidad que se considerara dicha época como una "economía de guerra" (Wagner, 2007). El clima generalizado de la crisis social se correspondió con la crisis económica para el caso de Guatemala (Palencia, 2010: 54).

Desesperadamente, el Estado enfrentó la crisis de gobernabilidad y del capital a través del proceso de exterminio, disciplina y terror contrainsurgente. Pero, al mismo tiempo, impulsaba un nuevo modelo de atracción de inversión extranjera basado en las maquilas de confección y la diversificación productiva del agro. El capital que había huido del peligro revolucionario y de la inestabilidad política en Guatemala, terminó volviendo a medida que se había disciplinado el trabajo alzado y se aprovechaban dichas condiciones para contratar la ingente cantidad de personas pobres de las áreas marginales de la ciudad de Guatemala. La maquila es, en este sentido, un campo particular de apropiación de plusvalía en el cual se sintetiza la reconfiguración del Estado y el capital con el arribo de las políticas neoliberales. A medida que se redactó una nueva Constitución en 1986 y se instauró el gobierno civil de Vinicio Cerezo, la lógica mundial del capital neoliberal se construyó en Guatemala bajo la sangre provocada por el exterminio social contrainsurgente. Así pues, las políticas de apertura económica, de privatización de sectores estatales y concesiones de recursos naturales, fueron creando las condiciones de aprovechamiento e instrumentalización del trabajo para convertirlo en plusvalor. La apertura democrática permitió una mayor manifestación social en campos que se consideraran controlables, pero otros movimientos, como el de personas que exigían conocer el paradero de sus familiares secuestrados, siguieron siendo perseguidos. Todavía entre 1986 y 1995 se cometieron acciones represivas contra líderes y lideresas de movimientos sindicales, magisteriales y estudiantiles, así como se mantenía bajo ataque a las Comunidades de Población en Resistencia (CPR) del norte de Quiché y Huehuetenango.

No obstante, el marco internacional a partir de inicios de los noventas, provocó grandes cambios en la convulsa área centroamericana. Los sandinistas habían perdido el control estatal tras las elecciones de 1990 y en El Salvador la guerrilla había firmado con el gobierno los Acuerdos de Paz en 1992. La negociación en Guatemala se topaba con la renuencia de ciertos sectores del ejército; esto, debido a que consideraban sin razón negociar con un enemigo militarmente inferior. Asimismo, sectores de la elite económica temían que 
los Acuerdos de Paz pusieran en riesgo la propiedad de sus tierras, que se acordara un incremento general de los impuestos o que se "fragmentara" el país por la demanda de autonomía indígena. ${ }^{5}$ Ahora bien, la presión internacional se fue haciendo cada vez más fuerte por un fin al llamado "Conflicto Armado Interno", con lo que se fueron convocando primero a mesas de diálogo entre los dirigentes de la Unidad Revolucionaria Nacional Guatemalteca (URNG) y el gobierno. Consecuentemente, se abrieron los canales de diálogo institucional para la sociedad civil y se aprovechó el contexto internacional favorable a los discursos de mujeres y pueblos indígenas. Ahora bien, icómo se hizo presente el movimiento maya en el Estado? Para esto esbozaremos previamente una crítica a la manera de entender el poder en el Estado y el capital.

\section{El Estado y el capital: dialéctica del carácter móvil y estático del poder}

Existen dos peligros constantes cuando se realiza un análisis político. El primero consiste en tomar categorías fijas de teoría política para entender la conflictividad social. Así por ejemplo, cuando se estudia un movimiento desde la política estatal, puede resultar capcioso el intento de comprender los cabildeos a través de categorías como sociedad civil, sistema político y Estado. El segundo peligro se deriva del primero: si se estudia la conflictividad encauzada en instituciones o movimientos sociales que quieren tener incidencia en las mismas, la forma específica de la política institucional-estatal puede fetichizar la manera como se aprehenden las relaciones sociales y la multiplicidad de la lucha. Dicho de otra forma, cuando el concepto explica la realidad social con pretensiones de objetividad externa, corre el peligro de ontologizar categorías - e instituciones - que son un producto particular e histórico-social.

Esto suele suceder cuando se toma la forma "Estado" como organización neutral donde se plantean las distintas posiciones políticas de la sociedad. El Estado es visto como un aparato que sirve para la aplicación instrumental de planes de gobierno, y que es dominado históricamente por determinados intereses particulares en detrimento de otros. Planteado así el marco de lucha, se percibe el poder como monopolio de una estructura fija, donde diversos grupos de la sociedad civil se disputan históricos privilegios y sistemas políticos. A semejantes conclusiones se llega desde las teorías marxista-leninista o estructuralista althusseriana, asi como la teoría política liberal de corte anglosajón, la misma que se ha dado en llamar New social movements. En ambas interpretaciones, el Estado adquiere un carácter objetivo ahistórico que, contradictoriamente, es visto como lucha histórica de clases, de hegemonía o soberanía sobre la maquinaria o aparato organizacional. Pero el énfasis puesto en delimitar la lucha social al canon estatal, fetichiza la comprensión de la actividad humana en proceso de liberación.

La tarea de la teoría crítica es rebasar el dato, la simple cosa o substancia en su fundamentación ontológica y descubrir su conformación como relación socio-histórica. Una vez comprendido el dato o la cosa en su génesis social, a través de su proceso, se puede poner en evidencia el carácter múltiple de la actividad humana en tanto que constructora o formadora de realidades históricas. La crítica a la cosificación ha estado implícita en la teoría social clásica, sobre todo en Marx y en Durkheim. Mientras en Marx se expresa como crítica a la fetichización de la mercancía, en Durkheim se entiende como crítica al sentido común o juicio valorativo frente al hecho social. Ambos captaron cómo la mercancía y el hecho social ejercen coacción sobre el individuo y la sociedad; sin embargo, solamente en Marx la crítica a la mercancía conlleva el cuestionamiento de la totalidad social enmarcada en el capitalismo. A nuestro parecer ese es el mayor mérito crítico de Marx: haber elaborado una teoría dialéctica donde demuestra cómo lo particular en la mercancía contiene lo universal de 
la dominación del sistema capitalista. La laguna que nos legó Marx es, no obstante, a nuestro parecer, no haber relacionado la fetichización de lo político con la figura del Estado, sino haberse planteado solamente la fetichización del producto social en tanto que mercancía, ignorando el despliegue político estatal en su lógica capitalista.

A pesar de ello, hay vetas invaluables que pueden servirnos en la actualidad para elaborar una teoría dialéctica del poder. Consideramos que los Manuscritos de 1857-1858 (Gründrisse) y el tomo II de El Capital, son especialmente certeros en el análisis de las formas y el movimiento del capital. A través del estudio de las formas que adquiere el mismo en el proceso de producción y circulación, Marx demuestra cómo la apropiación del plusvalor es un proceso donde las formas económicas se relacionan con el trabajo vivo según el momento en que se encuentre la relación. En este ensayo no detallaremos esta "teoría dialéctica del poder", con los grandes aportes que se pueden obtener de las reflexiones de Marx, Foucault, Fromm o Adorno. Lo que sí haremos será mostrar en qué sentido una teoría dialéctica del poder pone en entredicho la interpretación del Estado y el capital como entidades autónomas o dimensiones separadas. Posteriormente, esta exposición será central en la reflexión sobre el movimiento maya estatal y la lucha social. Veamos pues, tres características del poder desde la teoría dialéctica: a) el poder como proceso y relación social; b) el poder como despliegue en el cuerpo social en movimiento y estático; c) el poder como potencialmente superable por el rebasamiento de la actividad social liberadora.

El poder es un proceso y una relación social de conformación y producción de identidad, así como de encauce y represión de la no-identidad. La identidad aquí no es entendida solamente con base en el ser, sino en función de la actividad social. ${ }^{6}$ De manera que, cuando afirmamos que el poder conforma y produce actividad social bajo su identidad, estamos refiriéndonos al carácter concreto y material de lo que acepta de la actividad social del individuo o del grupo. Semejante es la represión que hace el poder de la no-identidad, desplegado como negación a lo que el poder no acepta como actividad social fuera de sus límites y cánones. Este planteamiento es similar a lo que Foucault (2006) afirma como los términos positivos y negativos del poder, aunque este autor haya desconfiado de la dialéctica por haberla subsumido a su forma hegeliana de síntesis. Por ende, el poder es objetivación de la subjetividad humana desde el doble proceso de lo que produce como identidad en el mismo y lo que rechaza o reprime por no serle idéntico. El poder, en nuestro momento histórico, en tanto que relación social concreta, tiende al sistema, a la lógica formal, a la transformación del ser humano en elemento intercambiable, al uso del mismo para fines externos. En resumen, el poder es actividad social alienada que se despliega, dependiendo el contexto históricosocial, en pos de la objetivación del ser humano y su instrumentalización con fines externos.

Es necesario constatar que el poder no es una posesión determinada en una posición. Más bien, el poder se despliega como "redes sociales" (Foucault, 1975) a través del cuerpo social, no determinado en un sólo punto de representación, sino en las relaciones que pone en movimiento. El poder es social en tanto que necesita reconocimiento, sea enseñado o impuesto, de los individuos o grupos sociales sobre los que dirige y actúa. Pero tan cierto es que el poder se materializa en figuras y posiciones sociales e institucionales, como lo es que dichas figuras ejercen poder por el reconocimiento o imposición que proviene de la red social.

Dicho esto, el poder no es una posesión individual sino una inserción y adecuación a la forma social. Es así como Foucault afirma que el poder no sólo es vertical, sino se inserta en el cuerpo social de manera horizontal y a través del mismo, conformando su lógica a través de individuos y grupos sociales. El poder, consiguientemente, lucha por imponer a la actividad 
social la identidad absoluta entre la totalidad social alienada y la particularidad. La plena identidad del poder se expresaría en la absoluta cosificación del ser humano en tanto que elemento y factor constituyente de un sistema cosificado y cosificante. El doble carácter del poder reside entonces en la manera en cómo se inserta, conforma, produce orden y lógica desde su actividad como flujo. ${ }^{7}$ Este flujo de dominación se expresa entonces como movimiento multiforme del poder, pero también, como el carácter estático que adquieren sus formas en una relación determinada. La forma estática es la percepción de un momento sincrónico del poder, pero que, entendido en su movimiento, es captado como parte del proceso conflictivo de producción e imposición social. Aquí la clave es entender el poder como movimiento y forma de dominación de actividad social a través del proceso de constitución de identidady de represión de la no-identidad.

Mas la teoría crítica del poder se hace dialéctica no en la naturalización de su lógica, sino en mostrar cómo la actividad social es más amplia y puede luchar contra la misma; es decir, en encontrar la posible ruptura y su ampliación. Aquíllegamos a la tercera característica del poder: no es absoluto debido precisamente a su forma sistémica. Si el poder es actividad social enajenada en expansión sistémica, el rompimiento de su cosificación puede ser el inicio de una actividad social liberadora. La lucha por la subjetividad humana comienza como negación de la subjetividad del poder, es decir, de la fuerza que adquiere la cosa frente al rebasamiento de la actividad humana en liberación. Ahora bien, icómo se plantearían estas tres características que hemos esbozado aquí para las relaciones concretas de poder en el Estado y el capital? Tanto en la teoría marxistaestructural como en la de los new social movements, se parte de la dicotomía del poder separado en el campo político del Estado y en el campo económico del capital. Sin embargo, desde una teoría dialéctica del poder, el Estado y el capital son dos formas de poder no separadas entre sí sino complementarias, atravesadas por el flujo de dominación. El Estado, según Weber (2002: 173-180), es la creciente separación entre los ciudadanos comunes y el aparato burocrático, es decir, entre el ciudadano concreto y la representatividad que delega en los profesionales de la política. De manera análoga, el capital separa a los trabajadores de los medios de producción. En ambos casos los seres humanos concretos son expropiados constantemente de la decisión sobre sí mismos y de los medios para vivir; la abstracción de la delegación de la soberanía popular es el punto central de la mistificación. La base de la sociedad capitalista y del Estado es la propiedad privada y la representatividad; ambas separan a los seres humanos concretos del proceso de autodeterminación social no basado en la explotación y la apropiación de plusvalía. Desde este momento, el poder no puede ser reducido en su análisis como factor perteneciente a una cosa, a una institución, a un Estado, porque sólo vería el despliegue de su forma sistémica pero no su conflictividad en el proceso de lucha social. Debido a que tanto el Estado como el capital son procesos paralelos y no simples cosas, relaciones y no dimensiones, la lucha contra el flujo de dominación que somete, ordena y aniquila, sólo puede hacerse, en la actualidad, teniendo en cuenta el doble carácter del poder: como movimiento y estado. La lucha anticapitalista es una lucha contra la propiedad privada y la representatividad, bases que permiten a la sociedad burguesa la explotación y la enajenación del proceso de autodeterminación social humana.

Tomando en cuenta este breve esbozo de la teoría dialéctica del poder, icómo entendemos concretamente el movimiento maya estatal? En el siguiente apartado describiremos brevemente el desarrollo del movimiento maya, haciendo especial énfasis en el enfocado en el Estado y la lógica que adquirió a medida que se consolidaba institucionalmente. Luego, reflexionaremos sobre el movimiento maya estatal tomando en cuenta la crítica al Estado y al capital como conformación del flujo de dominación. 
III. Movimiento maya estatal y reconfiguración de la dominación capitalista

Existen tres momentos centrales para comprender la paulatina conformación del movimiento maya estatal. ${ }^{8}$ En primera instancia, la apertura democrática del Estado guatemalteco en 1986 con la llegada de los gobiernos civiles. En segunda instancia, el clima de reflexión propiciado tanto por los Quinientos Años de lucha indígena, como por la entrega del Premio Nobel de la Paz a Rigoberta Menchú. Un año antes de la entrega, en 1991, se convocó en Quetzaltenango, Guatemala, al Segundo Encuentro Continental de la Campaña de los Quinientos Años de Resistencia en el Continente (Brett, 2010: 67). Esta campaña de reivindicación de la lucha indígena en América Latina formaba parte de las nuevas lógicas de reivindicación mundial, ante todo, la de hacer de la identidad particular un discurso alejado de los universalismos revolucionarios y estatalesmodernizantes. Desde 1968 se venían haciendo notorias diversas luchas particulares basadas en las mujeres, los indígenas, el Black Power, el movimiento ecologista, homosexual, entre otros. En el contexto de Guatemala es necesario advertir que las diferencias entre las posturas revolucionarias y los llamados indigenismos culturalistas databan, por lo menos, desde 1970. La diferencia entre ambas era la preeminencia de la identidad en la lucha y la aproximación al Estado. Mientras para los revolucionarios la identidad de clase predominaría sobre la lucha antirracista, para los indigenismos culturalistas la identidad indígena se contraponía al ladino o mestizo discriminador que, a su vez, daba el tinte racista al Estado. Por ende, su objetivo era acabar con el Estado racista y crear formas de gobierno indígena, aunque dejaba poco clara su interpretación de la explotación económica o, incluso, abogaba por una burguesía indígena como punta de lanza reivindicativa (Guzmán-Böckler y Herber, 1970: 100-101).

En tercer lugar tenemos el inicio del diálogo para la firma de los Acuerdos de Paz para poner fin al llamado
Conflicto Armado Interno. Como mencionábamos arriba, el Estado guatemalteco, interesado en suscribir los Acuerdos de Paz con URNG, abre las posibilidades del diálogo luego de varias décadas donde la represión y el silencio eran regla común. En este contexto, distintas organizaciones sociales de diversa índole (campesina, étnica, derechos humanos) posicionan sus demandas como representantes de la sociedad civil. Entre las organizaciones llamadas a exponer sus demandas frente al Estado, se empezaron a perfilar distintas agrupaciones que tenían en común pertenecer y representar a los pueblos indígenas de Guatemala. Los representantes de distintas organizaciones indígenas comienzan a demandar el derecho a ser reconocidos como mayas, promoviendo distintos derechos culturales y exigiendo el reconocimiento estatal del genocidio realizado contra los pueblos indígenas. Según Bastos (2007: 59), es a inicios de la década de 1990 cuando se constituye el movimiento maya, destacado primordialmente por demandas basadas en el "alejamiento de los planteamientos insurgentes" (ibídem). Así se crea un movimiento que tenía la virtud de no estar enmarcado en las decisiones de los dirigentes de las organizaciones guerrilleras, sino de reivindicarse de manera casi autónoma frente al Estado. Bastos considera que es en este periodo cuando se consolida una dicotomía en el movimiento maya, estando por un lado aquel sector que buscaba el reconocimiento de derechos específicos del pueblo maya $y$, por el otro, aquel constituido alrededor de las demandas populares vinculadas a la izquierda en Guatemala. A partir de estas condiciones, se fueron escuchando las reivindicaciones mayas frente al Estado durante los años precedentes a la Firma de la Paz, como fue constatado con la aprobación en 1995 del Acuerdo de Identidad y Derechos de los Pueblos Mayas. El Acuerdo de Paz se firmó finalmente el 29 de diciembre de 1996. Posteriormente, el movimiento maya continuó sus luchas a través de la preparación de la Consulta Popular de 1999. 
Existen diversos estudios acerca del movimiento maya, así como de sus posibles logros y errores históricos. Si bien la bibliografía es amplia, en este trabajo nos enfocaremos en ensayos recientes de dos estudiosos de dicho movimiento. El primero se titula La política maya en la Guatemala posconflicto (2010), escrito por el antropólogo español Santiago Bastos; tal vez quien más ha trabajado sobre el movimiento maya en Guatemala y quien, sin duda, ha aportado la secuencia histórica del mismo. El segundo trabajo tiene por título De movimiento indígena a complejidad política: la evolución de las políticas indígenas 1996-2007 (2010), redactado por el politólogo y antropólogo británico Roddy Brett, quien ha enfatizado el análisis de los conflictos en Guatemala a través de la teoría de los movimientos sociales. Ambos son autores de varios libros que aluden, en general, a la historia contemporánea de Guatemala, pero aquí nos referiremos solamente a los argumentos centrales de los ensayos mencionados, debido a que fueron escritos como reflexión específica del movimiento maya.

El ensayo de Bastos se basa en un análisis histórico de los principales hitos que dieron origen a los diversos movimientos mayas. Para el autor es necesario distinguir los movimientos mayas con discurso culturalistaespiritual, de aquellos con demandas populares campesinas, en contra de los megaproyectos y por una transformación agraria. De hecho, una de las principales características del movimiento maya estatal es que, inicialmente, se mantenían en tensión las negociaciones reivindicativas culturalistas y populares. Sin embargo, a medida que avanzaba el proceso de la Firma de la Paz, el Estado dio preeminencia a las demandas que no cuestionaran temas complicados como la tenencia de la tierra, la demanda por la autonomía regional y la de una transformación radical del currículum educativo. Prefirió abrirse un diálogo con temas que fuesen menos controversiales o, por lo menos, que no pusieran en cuestionamiento radical las bases de las relaciones económicas, simbólicas y de "unidad nacional" del Estado guatemalteco. Esto dio lugar a que se tomaran las reivindicaciones por la tierra y por la autodeterminación como lastres de la "anacrónica" izquierda revolucionaria, prefiriéndose mantener un diálogo con el Estado y así obtener reformas asequibles en lugar de transformaciones sociales importantes. Según Bastos: “[...] la izquierda indígena va abandonando los discursos de clase y los étnicoculturales se hacen, si no únicos, sí hegemónicos. Así 'o cultural' opaca esas otras dimensiones del 'ser maya', llegándose a lo que podemos llamar 'omniculturalidad': considerar todos los fenómenos sociales sólo desde la dimensión étnica, y tomar esta dimensión sólo en su componente cultural." (Bastos, 2010: 21).

En este sentido el multiculturalismo en el contexto guatemalteco se basó en una negación de las históricas demandas populares y, por el contrario, se tendió a considerar la marginación histórica como un asunto de culturas o etnias contrapuestas, desligándose de la intrínseca relación de clase en la conformación del statu quo. El movimiento maya enfocado en el Estado hizo de lo cultural, del respeto a la diferencia y del discurso antirracista, una bandera para interferir en el Estado e insertarse en posiciones prudentes al proceso, o bien desde instituciones estatales indígenas. Bastos acierta al criticar en el movimiento maya - al que no le hace la especificación de estar enfocado en el Estado- su tendencia a separarse de las comunidades, a crear un discurso en función del Estado y la Cooperación Internacional, y a encerrarse en un elitismo que se legitima a través de su imagen de representantes de los mayas.

Similar posición desarrolla Roddy Brett en su trabajo. Para Brett, el Estado guatemalteco se ha legitimado internacionalmente a través de la aceptación del discurso indígena, estimulando la creación de instituciones contra el racismo, por los derechos de las mujeres indígenas y el fomento cultural-espiritual. El autor considera que la falta de compromiso del Estado guatemalteco hacia los indígenas se refleja, en parte, en el poco apoyo presupuestario y en la ínfima incidencia 
política de los indígenas burócratas. De manera que lo que se apoya es más bien el discurso que legitima y no la capacidad de incidencia real en la transformación desde el Estado. Dicho de otra forma, se hace de lo indígena una parte necesaria de la representatividad nacional y se fomenta la nueva figura del "indigenócrata" (Brett, 2010: 81). Con esto, según Brett, no se rompe el monopolio de poder por parte de los presidentes ladinos y mestizos en el Estado, y a la vez se cierran las posibilidades de un presidente indigena de representatividad indígena. De cualquier forma, lo que critican Bastos y Brett del movimiento maya - estatal - es el haber reducido la participación política activista por una de legitimación elitista basada en lo maya, lo cual no permite que haya un verdadero cuestionamiento de la marginación de los indígenas. El horizonte de Bastos y Brett es aquel donde el Estado ha podido, hasta cierto punto, agenciarse de los elementos reivindicativos mientras reproduce, en sus gobiernos ladinos y neoliberales, esquemas de marginación indígena. Ahora bien, veamos de qué manera estas críticas pueden hacerse más certeras si se cuestiona de raíz la forma política del Estado en tanto que flujo de dominación y, de modo igualmente importante, retomando la crítica a la reconfiguración del capital.

Tanto Bastos como Brett elaboran un análisis histórico del movimiento maya consecuente con la idea de la mediación estatal como paso necesario de las transformaciones sociales. Ambos critican la marginación histórica de los pueblos indígenas en el Estado y, de acuerdo a esta idea, vieron en el movimiento maya una oportunidad para superar dicha marginación. Sin embargo, a nuestro entender, ambos autores parten de postulados teóricos que fetichizan las instituciones y el Estado como campos políticos par excellence, lo cual termina invisibilizando la reconfiguración del capital en el cuerpo social. En ambos ensayos dejan de lado cómo las relaciones capitalistas han cambiado y profundizado en la sociedad guatemalteca, repercutiendo sobremanera en nuevas lógicas de relaciones sociales y transformaciones en los patrones de dominación. Si bien Bastos en otros trabajos ha estudiado la explotación de clase como una "dimensión" más de opresión y Brett ha hecho un libro sobre la guerra en Guatemala, ${ }^{9}$ ambos han reducido el análisis a una forma política estatal, con sus lógicas y estrategias, dejando de lado los mismos procesos de lucha que no se ciernen bajo la representatividad y la propiedad privada. Se ha criticado la formación de elites burocráticas mayas, la separación de las "bases" comunitarias y el divorcio de las demandas populares a favor de lo cultural y étnico, pero todo esto no se ha criticado desde la reconfiguración general del Estado y del capital en tanto que flujo de dominación. Al decir esto queremos destacar el vínculo intrínseco entre la forma política del Estado legitimado por los Acuerdos de Paz y los procesos paralelos de privatización, maquilas, concesiones mineras e hidroeléctricas, reconversión de la agroexportación con la palma africana, la creciente importancia de la liberalización económica y financiera, así como de los Tratados de Libre Comercio. El movimiento maya estatal, a nuestro entender, tiene sus límites en la propia forma política que adoptó el Estado luego de la contrainsurgencia y del exterminio social entre 1980-1983 y, paulatinamente, con la disciplina social impuesta por medio de la reconfiguración de las relaciones capitalistas bajo los gobiernos civiles desde 1986.

Se ha criticado que el Estado multicultural guatemalteco ha utilizado lo indígena y maya como premisa de legitimación social desde sus políticas neoliberales (Hale, 2007). No obstante, si bien es cierta esta crítica, se queda a medias como los análisis de Bastos y Brett. Como analizábamos anteriormente, la base del proceso de conformación de poder es la separación. El Estado, basado en la representatividad ciudadana como delegación de soberanía, está basado en la separación entre el ser abstracto bajo la figura de los ciudadanos y la actividad social concreta. El Estado se legitima en la representatividad social de los ciudadanos, entendidos estos últimos como libres 
e iguales, homogéneos frente a la ley. La separación del proceso de producción capitalista se refleja en las instituciones que conforman su poder; es decir, el hombre abstracto, libre, ciudadano, igual, como forma política del valor de cambio. En el Estado multicultural la situación se repite bajo una lógica similar: la diferencia y la variedad son la base de la legitimidad del Estado, la desprestigiada figura del ciudadano occidental se ve superada, supuestamente, por la aceptación institucional de los otros grupos sociales "minoritarios". El Estado multicultural reconfigura al anacrónico ciudadano blanco occidental en el novedoso hombre/mujer/homosexual/indígena/afroamericano/ciudadano universal. La diferencia es aceptada y la reconciliación mundial pareciera haber llegado. Pero la base de la explotación capitalista en la separación se reproduce en la escisión entre el ser de lo aceptado por diverso y la actividad social que está obligado a hacer ese ciudadano diverso. En todo caso se acepta la diferencia en el ser político, pero jamás en la no-identidad de la actividad humana bajo los cánones sistémicos del capitalismo y del Estado. El movimiento maya estatal desplegó esta contradicción como antinomia necesaria de su inserción en la forma política del capital. Paradójicamente, hizo de la diferencia cultural su arma para ingresar al Estado y, a cambio, homogenizó la no-identidad de la actividad de las comunidades indígenas concretas (e.i. Kaqchikel, K'iche, Q'eqchi'). Para acceder al Estado subsumió la variedad de la actividad social de las comunidades indígenas al canon de lo cultural y espiritualmente reglamentado, estandarizado y generalizado frente al Estado. Es decir, hizo del ser maya la categoría abstracta de ciudadano, desprovisto de la actividad y del sufrimiento concreto que necesitaba el Estado contrainsurgente con ínfulas de democracia moderna.

Es por eso que afirmamos que la política estatal tiende a elevar al panteón democrático la diferencia del ser maya, siempre y cuando la condición sea que los indígenas de carne y hueso no se rebelen contra la propiedad privada de las fincas, no se organicen contra la minería y la hidroeléctrica, no quieran tomar en sus manos la dirección de sus comunidades por encima de la orden estatal. La forma Estado/capital y la autodeterminación de la actividad humana son contraposiciones; la liberación no se puede entender desde el punto de vista de una política progresiva estatal, sino como un proceso de rompimiento con la dominación. Pero la actividad liberadora parte de su experiencia particular de explotación y dominación, no de figuras abstractas. Es por eso que la lucha no puede ser representada por nadie, precisamente porque nace en la experiencia de la liberación y no se concede a sus supuestos representantes. El temor del poder sigue latente ahí donde los seres humanos, desde su particularidad histórica de opresión, se cuestionan su mundo y a sí mismos. Una doble realidad constata quien cuestiona el mundo desde el dolor que siente particularmente. Por un lado, el dolor y el hambre al que se ve sometido se pone de relieve como una forma histórica injusta que ha llegado a convertirse en estado natural; por lo tanto, desde su particularidad histórica niega la injusticia y lo que se le ha llegado a imponer. Por otro lado, la constatación del dolor particular remite al dolor general, a una comprensión y actuación amplia que despliega la liberación hacia el universal en construcción: la humanidad redimida. La lucha de los pueblos indígenas parte de su experiencia histórica de explotación y maltrato, pero se amplía más allá de una lucha particularista contra el racismo o por los derechos culturales. Antes bien, la lucha contra el racismo y la noidentidad de la actividad indígena necesita ampliarse al cuestionamiento de las condiciones que mantienen la pobreza, la marginación, las enfermedades. Una lucha contra el racismo puede irse ampliando, a su vez, hacia una lucha contra el capitalismo y la unilateralidad violenta del Estado. Dicho de otro modo, la actividad social liberadora abre lo nuevo sin nombre a partir de lo anquilosado nombrado pero, también, retoma del pasado la fuerza emancipadora aplastada contra la figura vacía del progreso lineal. 
Aquí reside la dialéctica de la liberación. Los seres humanos concretos despliegan la historia del dolor y la derrota como fuerza redentora viva, renovada de la ampliación de la actividad social humanizada, no determinada por el poder y la dominación. Concretamente, para el caso de Guatemala, es necesario criticar al Estado reconfigurado tras la contrainsurgencia y sus actuales mediaciones políticas (e.i. el movimiento maya estatal, pero también otras mediaciones). Dicha crítica es una tarea necesaria para repensar la transformación social radical, desde el país donde se ejecutó el exterminio contrainsurgente más grande de la historia contemporánea de América Latina.

\section{Notas}

1 Peor aún, antropólogos del discurso étnico, especializados en el movimiento maya de la década de los noventas, suelen interpretar de manera reduccionista la importancia de los gobiernos revolucionarios de 19441954. Uno de ellos, el español Santiago Bastos, a quien nos referiremos más adelante, llega a simplificar este momento afirmando que los gobiernos revolucionarios fueron un "paréntesis" cedido por la oligarquía guatemalteca a "los burócratas y militares ladinos" (Bastos, 2010: 13)

2 La diferenciación entre un poder directo y un poder indirecto (Marx), o bien, entre el poder del soberano y el biopoder (Foucault), es central para comprender la lógica de las relaciones de poder capitalistas y no capitalistas. Para un análisis más detallado consúltese: Palencia, S. (2010). “iPuede la lucha contra el racismo constituirse como una lucha contra el capital? Hacia un análisis del racismo desde la teoría crítica.", en: Revista Bajo el Volcán, no. 15. Puebla, México.

3 Para un estudio más detallado sobre las relaciones entre indígenas y ladinos campesinos con el gobierno de Árbenz véase: Grandin, Greg. (2007: 130). Panzós. La última masacre colonial. Guatemala: AVANCSO.
${ }^{4}$ Palabra utilizada por el ex comandante del EGP Gustavo Meoño. Entrevista diciembre 2010.

${ }^{5}$ Para un análisis de los Acuerdos de Paz consúltese las memorias del entonces Director de la Comisión Presidencial de la Paz (COPAZ), ex miembro de la guerrilla Gustavo Porras Castejón (2009).

${ }^{6}$ Esto no sigue necesariamente el concepto de identidad antropológica y de autoadscripción, sino que es más bien una propuesta para llevar el concepto filosóficosociológico de identidad de Theodor W. Adorno (1975) al plano del poder y la lucha.

${ }^{7}$ El concepto de flujo es utilizado por Marx en el tomo II de El Capital (2006: 27-90) para referirse a las distintas formas que va adquiriendo el capital en su relación de apropiación de trabajo. En la actualidad lo retoma John Holloway desde el análisis del flujo social del hacer y, en este ensayo, desde la teoría dialéctica del poder.

${ }^{8}$ Tal como lo afirman dos especialistas en la historia del movimiento maya, Bastos y Cumes, es más preciso hablar de diversos movimientos que canalizaron sus demandas y reivindicaciones a través del discurso de lo maya, con interpretaciones distintas y fines incluso lejanos entre sí. Lo que une los movimientos mayas es, en definitiva, el uso discursivo e identitario que se hizo del término para la unidad reivindicativa. En este ensayo nos enfocamos en una de sus variedades dominantes que, a través de su relación institucional con el Estado, ha logrado hegemonizar definiciones culturalistas, espiritualistas y de política civil basadas en el derecho a la diferencia.

${ }^{9}$ El libro de Bastos es coordinado en conjunto con Aura Cumes y se titula Mayanización y vida cotidiana (2007). El libro de Brett lleva el nombre de Una guerra sin batallas (2009).

\section{Bibliografía}

Adorno, Theodor (1975), Dialéctica Negativa. España: Editorial Taurus, pp. 330 
Bastos, Santiago (2007), Mayanización y vida cotidiana. La ideología multicultural en la sociedad guatemalteca, Vol. 1, Introducción y análisis generales/Santiago Bastos y Aura Cumes (coordinadores), Guatemala: FLACSOCIRMA, Cholsamaj.

Bastos, Santiago (2010), "La política maya en la Guatemala posconflicto" en Bastos Amigo, Santiago y Brett, Roddy (compiladores), El movimiento maya en la década de la paz(1997-2007), Guatemala: F\&\&G Editores, pp. 353.

Brett, Roddy (2010), “Demovimientoindígena a complejidad política: la evolución de las políticas indígenas 19962007", en Bastos Amigo, Santiago y Brett, Roddy (compiladores), El movimiento maya en la década de la paz (1997-2007), Guatemala: F\&EG Editores, pp. 353.

Morán, Rolando (2008), Construyendo caminos. Tres documentos históricos de la guerrilla guatemalteca. Guatemala: Centro Rolando Morán, pp. 184.

Cojtí, Demetrio (1997), Ri Maya moloj pa Iximulew. El movimiento maya (en Guatemala), Guatemala: Cholsamaj.

Durkheim, Émile (1999), Las reglas del método sociológico, España: Editorial Folio, pp. 188.

Falla, Ricardo (1993), Historia de un gran amor. Recuperación autobiográfica de la experiencia con las comunidades de Población en Resistencia. Ixcán, Guatemala, pp. 89.

Foucault, Michel (2006), Surveiller et punir, France: Gallimard, pp. 360.

Fromm, Erich (1964), Ética y psicoanálisis, México: Fondo de Cultura Económica, pp. 215.

Fromm, Erich (1964), El corazón del hombre. Su potencia para el bien y para el mal, México: Fondo de Cultura Económica, pp. 179.

Guzmán Böckler, Carlos. Jean-Loup, Herbert (1970), Guatemala una interpretación histórico-social, México: Siglo XXI, pp. 205.

Hale, Charles (2007), "Más que un indio". Ambivalencia racial y multiculturalismo neoliberal en Guatemala, Guatemala: AVANCSO, pp. 351.
Holloway, John (2003), Cambiar el mundo sin tomar el poder, Buenos Aires: Ediciones Herramienta.

Marx, Karl (1980), Grundrisse. Manuscrits de 1857-1858, Tomo I, Paris: Éditions Sociales.

Marx, Karl (2006), El Capital II. Crítica de la economía política, México: Fondo de Cultura Económica, pp. 623.

Palencia, Sergio (2010), "Conformación histórica del capitalismo en Guatemala (1944-1983). Finca agroexportadora, represión social y maquila", en Palencia, S. (coordinador), Mendizabal, Mónica y Poroj, Manuel, Reconfiguración del capital en Guatemala en maquilas de confección y Call Center. Guatemala: FOCINEG, pp. 229.

Palencia, Sergio (2010), "Compañeros, yo me voy al campo". Reflexiones desde el exterminio de la rebelión indígena en Guatemala (1980-1982), borrador, pp. 18.

Porras Castejón, Gustavo (2009), Las huellas de Guatemala, Guatemala: F\&G editores, pp. 459.

Tischler, Sergio (2001), Guatemala 1944: crisis y revolución. Ocaso y quiebre de una forma estatal, segunda edición, Guatemala: F\& $\&$ editores, pp. 353.

Tischler, Sergio (2010), Guatemala 1954. La sintesis reaccionaria del poder y la revolución inconclusa, borrador, pp. 18

Vela, Manolo (2008), "Guatemala, 1954. Las ideas de la contrarrevolución", en Masas, armas y élites. Guatemala, 1820-1980. Análisis sociológico de eventos históricos, Guatemala: FLACSO, pp. 165.

Wagner, Regina (coordinadora general) (2001), Historia del café en Guatemala, Guatemala: Villegas editoresAnacafé, pp. 223.

Wagner, Regina (2007), Historia del azúcar en Guatemala, Guatemala: Editorial Galería/Guatemala de Fundación G\&ET Continental-Asazgua, pp. 334.

Weber, Max (2002), Economía y sociedad. Esbozo de sociología comprensiva, México: Fondo de Cultura Económica, pp. 1237. 